\title{
The Effect of the Aqueous Enzymatic Extraction Method towards Momordica charantia Seed Oil and Its Lignocellulosic Biomass
}

\section{Nadirah Zawani MOHD NESFU ${ }^{1,5}$, Hasnah OSMAN ${ }^{1, *}$, Suriyati MOHAMAD ${ }^{2}$, Lionel MUNIGLIA ${ }^{3}$, Nicolas BROSSE ${ }^{4}$, Dominique LAURAIN-MATTAR ${ }^{5}$, Rosella SPINA ${ }^{5}$ and Ezatul E. KAMARULZAMAN ${ }^{6}$}

${ }^{1}$ School of Chemical Sciences, Universiti Sains Malaysia, 11800 Minden, Penang, Malaysia

${ }^{2}$ School of Biological Sciences, Universiti Sains Malaysia, 11800 Minden, Penang, Malaysia

${ }^{3}$ LiBio, ENSAIA, 2 Avenue de la Forêt de Haye, Université de Lorraine,

54505 Vandoeuvre-lès-Nancy, France

${ }^{4}$ LERMAB, Faculté des Sciences et Technologies BP 70239, Université de Lorraine,

54506 Vandoeuvre-lès-Nancy, France

${ }^{5}$ UMR CNRS 7565 SRSMC, Faculté des Sciences et Technologies BP 70239, Université de Lorraine, 54506 Vandoeuvre-lès-Nancy, France

${ }^{6}$ School of Pharmaceutical Sciences, Universiti Sains Malaysia, 11800 Minden, Penang, Malaysia

("Corresponding author's e-mail: ohasnah@usm.my)

Received: 2 November 2019, Revised: 12 March 2020, Accepted: 22 April 2020

\begin{abstract}
The development of a sustainable product using natural resources will gain much attention nowadays. This work aimed to study the effect of aqueous enzymatic extraction (AEE) using a different ratio of enzyme cocktails HEL1 and X7 towards the production of Momordica charantia $L$. (M. charantia) seed oil and to identify the composition of the seeds' lignocellulosic biomass (extracted-free materials, EFM). The M. charantia seed oil contained omega-3 fatty acids, such as stearidonic acid, that possess hypotriglyceridemic properties. The oil obtained was derivatized to fatty acid methyl esters (FAMEs) before biochemical quantification using gas chromatography (GC). The EFM was subjected to Soxhlet extraction and further analyzed to identify lignin, acid-soluble sugars, and hemicellulose composition. The results showed that the highest seed oil percentage, $(6.26 \pm 0.53 \%)$ was extracted from M2 sample using a combination of $5 \%$ HEL1 to $1.25 \%$ X7 enzyme cocktails, as compared to the extraction without enzyme $(3.32 \pm 0.38 \%)$. The percentage of stearidonic acid in the seed oil increased from $13.55 \%$ (without enzyme) to $19.43 \%$ (M2), proving that there were some change in terms of fatty acid composition in the seed oil.
\end{abstract}

Keywords: Momordica charantia L., Seeds, Aqueous enzymatic extraction, Lignocellulosic biomass

\section{Introduction}

Momordica charantia L. (M. charantia), from the Cucurbitaceae family, is a thin climbing vine with long-stalked leaves that usually flowers from July to August and is cultivated as a vegetable in Asia, Africa, and the Caribbean. M. charantia plant can adapt to a wide range of climates, but grows best in warm weather. Figure 1 shows a cross-section of $M$. charantia fruits. It is also known as bitter melon, balsam pear, bitter squash, or bitter gourd. 


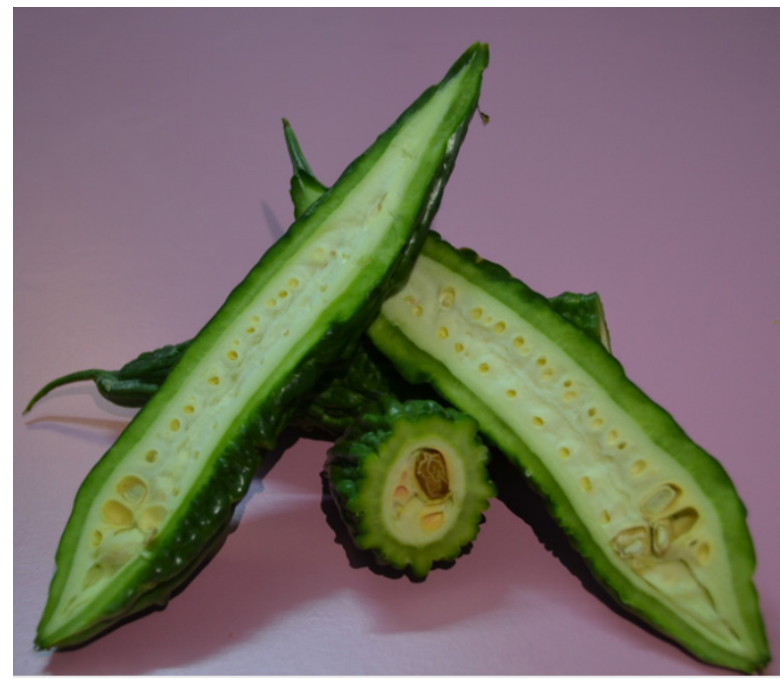

Figure 1 Cross-section of $M$. charantia fruit.

The local Malay name for this plant is "peria katak". The bitter taste of the fruit is attributed to the presence of cucurbitacin-like alkaloids, momordicin, and triterpene glycoside [1,2]. Bitter melon is also used in traditional medicine to treat a variety of ailments. The indigenous people of the Amazon drink the tea from the leaves to expel intestinal gas and to promote menstruation, as well as to reduce blood sugar levels for diabetic patients [3]. The use of bitter melon fruit as a natural remedy for treating diabetes is a common practice among the local population of Asia, Africa, and the Caribbean [4]. Many studies have reported that the hypoglycemic properties of $M$. charantia are induced by the presence of steroidal glycosides [5-7], insulin mimetic lectins [8], and triterpenoids [9,10]. However, most of the studies focused on the leaves, pulps, and stems of $M$. charantia. The seeds are discarded without any further uses. Some studies have shown that the seeds of $M$. charantia contain a high content of omega-3 polyunsaturated fatty acids, such as $\alpha$-linolenic acid, eicosapentaenoic acid, stearidonic acid, and $\alpha$ eleostearic acid [11-13]. Dietary intake of omega-3 polyunsaturated fatty acids is known to lower triglyceride content in humans, as the polyunsaturated fatty acids can attach to and clear out the unhealthy fats [14]. According to Chen et al., the $\alpha$-eleostearic acid presence in bitter melon seed oil could reduce hepatic triglyceride accumulation [15].

In Malaysia, approximately 122.80 hectares of farmland is planted with M. charantia, which can produce a total of 1372.46 metric tons of $M$. charantia fruits every year. In accordance, about 548.984 metric tons of $M$. charantia seed, that can be used to produce seed oil, are being discarded every year in Malaysia [16]. This is a waste of natural resources, as the extraction of oil from the seed can easily be carried out using many methods. With the increasing demand for oilseed from agricultural plants, oil extraction technology has become more advanced, such as the alternative solvent extraction methods including supercritical fluids [17], enzyme-assisted aqueous extraction (AEE) [18], and microwaveassisted extraction [19].

AEE is getting some attention nowadays due to its efficient, sustainable, and eco-friendly characteristics. This extraction process depends on the specific properties of the enzyme itself. The enzyme, acting as a catalyst under optimum experimental conditions, disrupts the plant cell wall by hydrolyzation to release the intracellular components [20]. The plant cell walls are a complex structure, mainly made of cellulose, hemicellulose, lignin, and protein, in addition to pectin [21,22]. Rosenthal reported that the cell wall degradation enzyme for rapeseed consists of a combination of pectinase, cellulase, and hemicellulase [23]. In a previous study, Latif and Anwar reported that the active mechanism of enzyme cocktail (Alcalase 2.4L, Viscozyme L, Protex 7L, Natuzyme, and Kemzyme) 
during AEE was the degradation of cellulose, pectin, and protein. Thus, the destruction of structural cell wall integrity led to higher sesame oil recovery; $16.5-24.8 \%$ for AEE was observed, compared to only $12.3 \%$ for the control (without enzyme treatment) [24].

The seed residue or lignocellulosic biomass obtained from the AEE method is known to have different hemicellulose compositions, as the enzymatic hydrolysis is influenced by both the structural features of cellulose and the mode of enzyme action. Given the advantages of this extraction technology, this research study aimed to highlight the essential characteristics of the $M$. charantia seed oil using a specific AEE method, and the seed biomass compositions, such as lignin, soluble sugar, uronic acid, and hemicellulose, after the AEE method.

\section{Materials and methods}

\section{Seed sample preparation}

Unripe M. charantia fruits were purchased from a vegetable farm in Ara Kuda, Seberang Perai Utara, Penang, Malaysia, between June and August 2015. The seeds were separated, cleaned, and sundried. The seed samples were stored in polyethylene bags under vacuum for further processing.

\section{Aqueous enzyme extraction of seed samples}

AEE was performed to extract oil from the $M$. charantia seed according to the method as described by Muniglia et al. [25]. The enzyme cocktails, HEL1 and X7, were blended in the Laboratoire D'ingénierie des Biomolécules (Nancy, France). The enzyme cocktail HEL1 contained the average mixture of cellulase $(45.0 \mu \mathrm{mol} / \mathrm{min} / \mathrm{mL})$, hemicellulase $(7.0 \mu \mathrm{mol} / \mathrm{min} / \mathrm{mL})$, betaglucosidase $(4.5$ $\mu \mathrm{mol} / \mathrm{min} / \mathrm{mL})$, endocellulase $(27.0 \mu \mathrm{mol} / \mathrm{min} / \mathrm{mL})$, exocellulase $(9.0 \mu \mathrm{mol} / \mathrm{min} / \mathrm{mL})$, arabinase $(465.0$ $\mu \mathrm{mol} / \mathrm{min} / \mathrm{mL})$, xylanase $(300.0 \mu \mathrm{mol} / \mathrm{min} / \mathrm{mL}), \quad$ galactanase $(750.0 \mu \mathrm{mol} / \mathrm{min} / \mathrm{mL})$, endopolygalacturonase $(61.0 \mu \mathrm{mol} / \mathrm{min} / \mathrm{mL})$, and pectin methylesteras $(1.0 \mu \mathrm{mol} / \mathrm{min} / \mathrm{mL})$ which aimed for cell wall degradation, while the enzyme cocktail X7 contained protease and pectinase, which aimed for protein degradation.

Initially, the freshly-ground dried $M$. charantia seeds were mixed with distilled water at a ratio of 1:4 into a pre-programmed bioreactor (Celligen Plus, New Brunswick Scientific, U.S.A.) with continuous stirring. Then, the enzyme cocktails were added consecutively into the bioreactor once the temperature of the bioreactor reached $50{ }^{\circ} \mathrm{C}$, starting with HEL1, followed by X7, at their different ratios (Table 1). The reaction was left to carry on for $4 \mathrm{~h}$ in the bioreactor, followed by centrifugation $(0.158$ kilohertz, $20 \mathrm{~min}$, $20{ }^{\circ} \mathrm{C}$ ) to separate the products. The final products of this extraction process were: 1) oil, 2) seed residue, and 3) an aqueous part.

Table 1 Seed samples and their enzyme cocktail ratios.

\begin{tabular}{ccc}
\hline \multirow{2}{*}{ Seed samples } & \multicolumn{2}{c}{ Enzyme (\%)/Seed weight $(\mathrm{g})$} \\
\cline { 2 - 3 } & HEL1 & $\mathbf{X} 7$ \\
\cline { 2 - 3 } M0 & - & - \\
M1 & 5.00 & - \\
M2 & 5.00 & 1.25 \\
M3 & 5.00 & 2.50 \\
M4 & 5.00 & 5.00 \\
\hline
\end{tabular}


The seed oil samples were initially derivatized to fatty acid metal esters (FAMEs) using the esterification process as described by Metcalfe and Schmitz before being further analyzed to identify their biochemical compositions using gas chromatography (GC). The polar properties of underivatized fatty acid usually lead to the formation of hydrogen bonding, which results in adsorption issue. Hence, reducing their polarity by derivatization makes them more amenable for analysis [26]. Simultaneously, the seed residue was further analyzed to identify the lignin, soluble sugar, uronic acid, and hemicellulose compositions using the Soxhlet extraction method, ionic chromatography, and size exclusion chromatography (SEC). The aqueous part was discarded.

\section{Gas chromatography analysis of FAMEs}

Each derivatized oil (FAME) was analyzed to identify its biochemical composition using flame ionization detector gas chromatography (GC-FID), as it is the most suitable detector to detect organic compounds or any easily-flammable substances with higher carbon concentrations. The detector responds to the presence of ionic substances, and the number of ions formed can be calculated. The peak area of $\mathrm{GC}$ chromatogram can then be used to determine the qualitative measurement of the eluate, as the peak area of the signal is proportional to the concentration of the compound. In this study, the analysis of FAMEs was carried out by using Shimadzu GC-2010 plus an instrument equipped with Zebron capillary GC column ZB-Wax, $60 \mathrm{~m} \times 0.25 \mathrm{~mm} \times 0.25 \mathrm{~mm}$. Pure helium gas was used as the carrier gas, pressurized and flowed at $141.2 \mathrm{kPA}$ and $11.7 \mathrm{~mL} / \mathrm{min}$, respectively. Then, $1 \mu \mathrm{L}$ of each FAME sample was injected into the GC and was separated using temperature programming, starting with $120^{\circ} \mathrm{C}$ and held for $2 \mathrm{~min}$, followed by heating to $180^{\circ} \mathrm{C}$ with a heating rate of $40{ }^{\circ} \mathrm{C} / \mathrm{min}$ and held for another 2 min, before the temperature was increased to $220^{\circ} \mathrm{C}$ with a heating rate of $3{ }^{\circ} \mathrm{C} / \mathrm{min}$, and held for another $25 \mathrm{~min}$. The fatty acid standards were used for calibration ( 7 points per curve). The reagents and standards were provided by Sigma-Aldrich and Fisher Scientific.

\section{Soxhlet extraction of seed residue}

The dried seed residue was further extracted using the Soxhlet extraction method to ensure all extractive components were removed before hydrolysis to determine their lignin and acid-soluble sugar contents. The presence of extractive components hinders the hydrolysis process by cross-reacting with acid and condensing to acid-insoluble components, resulting in inaccurate analysis. To execute the Soxhlet extraction, an amount of $50 \mathrm{~g}$ of each dried seed residue sample was loaded into an extraction thimble, which was placed into a Soxhlet extractor (Pyrex, U.S.A) fitted with a condenser (Pyrex, U.S.A) on an isomantle heater (Fisherbrand, U.S.A). Then, $250 \mathrm{~mL}$ of $n$-hexane was added into a $500 \mathrm{~mL}$ round bottom flask fixed to the Soxhlet extractor and heated at $n$-hexane boiling point $\left(68^{\circ} \mathrm{C}\right)$. The condensate dripped into the reservoir containing the thimble. The solvent from the reservoir was poured into a round bottom flask once the solvent level reached the siphon. The process was continued for $5 \mathrm{~h}$. Then, $n$ hexane was evaporated using a rotary evaporator (Buchi, Switzerland). The final products of the Soxhlet extraction process were: 1) extracted-free materials (EFM) and 2) extractive materials. The extractive materials were discarded, and the EFM was weighed and kept for further analysis.

\section{Determinations of lignin, soluble sugars, and uronic acid of EFM}

An amount of $175 \mathrm{mg}$ of each dried EFM sample was placed in a conical bottom centrifuge tube, and $1.5 \mathrm{~mL}$ of $72 \%$ sulfuric acid was added dropwise. The mixture was placed into a water bath and heated at $30{ }^{\circ} \mathrm{C}$ for $1 \mathrm{~h}$ with periodical stirring using a glass rod. A volume of $42 \mathrm{~mL}$ of distilled water was added into the mixture to achieve a concentration of $4 \%$ sulfuric acid by mass. The mixture was then autoclaved at $121{ }^{\circ} \mathrm{C}$ for $1 \mathrm{~h}$. The mixture was allowed to cool down to room temperature before being filtered. The filtrate was then diluted with $56.5 \mathrm{~mL}$ of distilled water in a volumetric flask. The resulting solution was further analyzed by high-performance anion-exchange chromatography with pulsed amperometry detection (HPAEC-PAD) (PerkinElmer, U.S.A) to determine its soluble sugar and uronic acid contents. The solid residue (lignin) was dried and weighed. Table 2 shows the seed sample codes for soluble sugar and uronic acid analysis. 
Table 2 Seed sample codes for acid soluble sugar analysis and their descriptions.

\begin{tabular}{ccc}
\hline \multirow{2}{*}{ Sample codes } & \multicolumn{2}{c}{ Enzyme (\%)/Sample Weight (g) } \\
\cline { 2 - 3 } & HEL1 & X7 \\
\hline $\mathrm{M} 0_{\mathrm{L}}$ & - & - \\
$\mathrm{M} 1_{\mathrm{L}}$ & 5 & - \\
$\mathrm{M} 2_{\mathrm{L}}$ & 5 & 1.25 \\
$\mathrm{M} 3_{\mathrm{L}}$ & 5 & 2.5 \\
$\mathrm{M} 4_{\mathrm{L}}$ & 5 & 5 \\
\hline
\end{tabular}

Note: $M$ refers to the EFM, which had undergone AEE, while, ${ }_{L}$ refers to the soluble sugar and uronic acid sample of the EFM.

\section{Determination of soluble sugar and uronic acid contents of EFM}

The separation and quantification of soluble sugars and uronic acids of the EFM were carried out using HPAEC-PAD operating on Dionex ICS-3000 system, which consisted of a gradient pump SP, a passer AS, an electrochemical detector ED operating with a gold electrode, a reference electrode $\mathrm{Ag} / \mathrm{AgCl}$, and Chromeleon version 6.8 (Dionex Corp, USA). A Carbopac PA20 column $\left(3 \times 150 \mathrm{~mm}^{2}\right.$, Dionex $)$ with a guard column $\left(3 \times 30 \mathrm{~mm}^{2}\right.$, Dionex $)$ was used in the stationary phase. The mobile phase was made of water, $250 \mathrm{mM} \mathrm{NaOH}$ in water, and $1 \mathrm{M} \mathrm{NaOAc} / 20 \mathrm{mM} \mathrm{NaOH}$ in water. A diluted $46-48$ $\%$ sodium hydroxide solution (Fisher Scientific) and anhydrous sodium acetate (Sigma Aldrich) in ultrapure water were used as eluents. The eluents were degassed with helium gas for 20 min before being injected. After each analysis, the column was flushed for $10 \mathrm{~min}$ with $250 \mathrm{mM} \mathrm{NaOH}$ solution and restored for $10 \mathrm{~min}$ to the initial conditions of the analysis. The samples were injected with an entire loop of $25 \mu \mathrm{m}$, and the separations were carried out at $35^{\circ} \mathrm{C}$ at a flow rate of $0.4 \mathrm{~mL} / \mathrm{min}$. The pulse sequence for pulsed amperometric detection consisted of potentials of $+100 \mathrm{mV}(0-200 \mathrm{~ms}),+100 \mathrm{mV}$ integration $(200-400 \mathrm{~ms}),+100 \mathrm{mV}(400-410 \mathrm{~ms}),-2000 \mathrm{mV}(410-420 \mathrm{~ms}),+600 \mathrm{mV}(430 \mathrm{~ms})$, and $-100 \mathrm{mV}$ (440 - 500ms) [27]. Soluble sugar and uronic acid standards were used for calibration (7 points per curve). The reagents and standards were provided by Sigma-Aldrich and Fisher Scientific.

\section{Hemicellulose extraction of EFM}

Initially, the EFM was subjected to the bleaching process to produce holocellulose. Sodium chlorite was used as the bleaching agent due to its moderately-active oxidation properties. The bleaching process was conducted by milling $1.5 \mathrm{~g}$ of each dried treated EFM sample into $0.05 \mathrm{~mm}$ size before being dispersed slowly into $125 \mathrm{~mL}$ deionized water in a $250 \mathrm{~mL}$ conical flask. Acetic acid glacial, $1 \mathrm{~mL}$, was added into the mixture, with an additional $1 \mathrm{~g}$ of sodium chlorite. The mixture was sealed and placed in a Julabo SW 22 shaking water bath at $70{ }^{\circ} \mathrm{C}$ for $2 \mathrm{~h}$. Then, another $1 \mathrm{~mL}$ of acetic acid glacial and $1 \mathrm{~g}$ of sodium chlorite were added consecutively into the reaction mixture with continuous shaking in the same conditions for $2 \mathrm{~h}$. The process was repeated until the color of the residue turned to white. The reaction mixture was filtered and washed thoroughly with deionized water. The holocellulose obtained was collected and dried overnight in a fume hood, which was then further reprecipitated into hemicellulose. An amount of $200 \mathrm{~mL}$ of $2 \% \mathrm{w} / \mathrm{v}$ sodium hydroxide aqueous solution was added into $10 \mathrm{~g}$ of each holocellulose sample in a round bottom flask and stirred for $2 \mathrm{~h}$ at $80{ }^{\circ} \mathrm{C}$. Then, an additional $200 \mathrm{~mL}$ of 2 $\% \mathrm{w} / \mathrm{v}$ sodium hydroxide aqueous solution was added into the reaction mixture and stirred for another 2 h. The $\mathrm{pH}$ of the mixture was adjusted to $5-6$ by adding $20 \% \mathrm{w} / \mathrm{v}$ acetic acid solution. The reprecipitation process of the mixture was repeated using $800 \mathrm{~mL}$ of ethanol. The precipitate formed was recovered by centrifugation. The percentage yield of hemicellulose was calculated and analyzed using Fourier-transform infrared (FTIR) spectroscopy (PerkinElmer, England), as well as SEC. 


\section{Determination of molecular weight distribution of hemicellulose by SEC}

The molecular weight distribution of hemicellulose was determined by SEC. The analysis was performed using a Hewlett-Packard 1090 series HPLC system consisting of an autosampler, a UV detector, and 3 columns of Styragel HR1, HR3, and HR4 (Waters Inc.) linked in series using tetrahydrofuran (THF) as the eluent. The hemicellulose was dissolved in $1 \mathrm{mg} / \mathrm{mL}$ of THF, and the solution was filtered through a $0.45 \mathrm{~mm}$ filter. Then, $20 \mathrm{~mL}$ of the filtered solution was injected into the system and was detected using a UV detector at $280 \mathrm{~nm}$. Data were collected using Agilent ChemStation rev. A.10.01 and analyzed using Agilent GPC Addon rev. A.02.02 software.

\section{Results and discussion}

Two different types of enzyme cocktails, namely HEL1 and X7, were used in this study to extract oil, soluble sugars, and uronic acid of $M$. charantia seeds. Table 3 shows that the introduction of enzyme cocktails into the batch reaction increased the percentage of extracted seed oil. In the control experiment, without the addition of enzyme cocktail (M0), only $3.32 \pm 0.38 \%$ of seed oil was extracted. The highest percentage seed oil $(6.26 \pm 0.53 \%)$ was extracted from M2 using a combination of $5 \%$ HEL1 to $1.25 \%$ X7 enzyme cocktails, followed by M4 $(5.03 \pm 0.28 \%)$ using a combination of an equal ratio of HEL1 and $\mathrm{X} 7$ enzyme cocktails.

The results indicated that cellulase, proteinase, and pectinase present in the enzyme cocktails HEL1 and X7 could facilitate the breakdown of cellular and subcellular structures of the seed to promote oil release. The enzymes could have weakened the vegetal cells in the seed to help release the oil [28]. In a previous study, Latif and Anwar [29] reported that the active mechanism of a selected enzyme cocktail during enzymatic aqueous extraction was the degradation of cellulose, pectin, and protein, thus destructing the structural cell wall integrity of the seed cells [29]. Additionally, the incorporation of enzymes may have cleaved the protein networks of the cotyledon cells and oleosin-based membranes that surround the lipid bodies of the seed cell wall, resulting in oil release [30,31]. The results also showed that the increment of enzyme cocktail X7 to HEL1 ratio was not proportional to the percentage of oil being extracted as the percentage of enzyme increment after M2 did not show any significant increase in the percentage of oil being extracted.

Table 3 Percentages of seed oil recovery by aqueous enzymatic extraction method using combination of different enzyme cocktail ratios.

\begin{tabular}{cc}
\hline Sample & Oil extracted (\%) \\
\hline M0 & $3.32 \pm 0.38$ \\
M1 & $4.67 \pm 0.11$ \\
M2 & $6.26 \pm 0.53$ \\
M3 & $4.10 \pm 0.44$ \\
M4 & $5.03 \pm 0.28$ \\
\hline
\end{tabular}

Note: The extraction process was triplicated.

The percentage of seed oil extracted $=\frac{\text { Weight of oil obtained }(\mathrm{mg})}{\text { Weight of dry seed used }(\mathrm{mg})} \times 100 \%$

The extracted seed oil samples (M0, M1, M2, M3, and M4) were subjected to derivatization into FAMEs before identification of their biochemical compositions by GC-FID since FAMEs are more volatile and more easily analyzed. GC-FID has been widely used in the separation and detection of 
FAMEs. The GC chromatogram revealed the presence of some common and non-essential FAMEs, as shown in Table 4. Seven known fatty acids were identified. Three unknown fatty acids were also detected. However, 3 unknown peaks of free fatty acids were observed from the chromatogram that were co-eluting almost at the same time. It is suggested that some compounds may co-elute more significantly in size and elute together at the end during separation [32,33]. Hence, 1 dimensional GC may not be the best option for FAME separation.

Table 4 FAME compositions of $M$. charantia seed oils of M0, M1, M2, M3, and M4.

\begin{tabular}{lccccc}
\hline \multirow{2}{*}{ Fatty acid } & \multicolumn{5}{c}{ Compositions (\%) } \\
\cline { 2 - 6 } & M0 & M1 & M2 & M3 & M4 \\
\hline Palmitic acid (C16) & $8.84 \pm 0.12$ & $7.21 \pm 0.09$ & $17.97 \pm 0.11$ & $17.26 \pm 0.10$ & $11.23 \pm 0.09$ \\
Stearic acid (C18) & - & - & $3.28 \pm 0.13$ & - & - \\
Elaidic acid (C18:1n9t) & $0.47 \pm 0.11$ & $8.06 \pm 0.08$ & $20.42 \pm 0.09$ & $28.06 \pm 0.11$ & $29.63 \pm 0.08$ \\
Oleic acid (C18:1n9c) & $35.80 \pm 0.08$ & $17.31 \pm 0.11$ & - & - & - \\
Vaccenic acid (C18:1n7) & $2.84 \pm 0.10$ & $5.02 \pm 0.09$ & $2.52 \pm 0.09$ & $5.02 \pm 0.11$ & $7.58 \pm 0.10$ \\
Stearidonic acid (C18:4n3) & $13.55 \pm 0.11$ & $13.42 \pm 0.11$ & $19.43 \pm 0.08$ & $16.42 \pm 0.08$ & $12.83 \pm 0.09$ \\
Paullinic acid (C20.1) & $6.50 \pm 0.12$ & $6.19 \pm 0.12$ & $13.51 \pm 0.11$ & $5.19 \pm 0.09$ & $2.41 \pm 0.10$ \\
Unknown 1 & $10.66 \pm 0.09$ & $10.14 \pm 0.09$ & $7.81 \pm 0.10$ & $15.14 \pm 0.09$ & $15.31 \pm 0.10$ \\
Unknown 2 & $9.55 \pm 0.11$ & $9.96 \pm 0.10$ & $6.00 \pm 0.10$ & $4.96 \pm 0.10$ & $8.69 \pm 0.11$ \\
Unknown 3 & $11.79 \pm 0.12$ & $8.83 \pm 0.11$ & $9.07 \pm 0.09$ & $7.98 \pm 0.11$ & $12.32 \pm 0.11$ \\
\hline
\end{tabular}

Note: Values are $\%$ of total fatty acid expressed as mean \pm SD of 3 separate determinations.

Based on the compositions of $M$. charantia seed oil (Table 4), the percentage of elaidic and palmitic acids increased with the introduction of the enzyme cocktails. In the control experiment (M0), only $0.47 \%$ of elaidic acid was present in the extracted oil. With the introduction of the enzyme cocktails, the percentage of elaidic acid increased to 8.06, 20.42, 28.06, and 29.63\% for M1, M2, M3, and M4, respectively. The presence of the enzyme cocktails showed a similar trend for palmitic acid, albeit with lesser increment. The oil release could be due to the presence of cellulase in the enzyme cocktail, which disrupted other polysaccharide constituents in the seed cell wall. The cellulase presence in HEL1 and X7 promoted an efficient cellulose degradation. The cellulase mechanism, described as the cleaving of internal glucosidic bonds within an unbroken glucan chain by endoglucanase enzyme, could result in the creation of a non-reducing chain of cellobiohydrolase substrate, cleaving the cellobiose dimers from the glucan chain that was released in the solution. Furthermore, $\beta$-glucosidase split the cellobiose dimer into glucose monomer, concluding the cellulose hydrolysis process [34]. The combination of enzymes played a dominant effect in disrupting the seed cell walls, which was also reported in other findings [35].

These results also showed that the oil composition differed with different X7 enzyme ratios. In M4, the percentage distribution of elaidic acid, vaccenic acid, palmitic acid, stearidonic acid, and paullinic acid increased with increasing ratio of X7. The results suggested that the enzyme cocktail X7 supported the reaction of enzyme cocktail HEL1 hydrolyzed the seed cellular structures as each enzyme cocktail consisted of different types of an enzyme mixture. It can be concluded that the $M$. charantia seed oil obtained from AEE exhibited slight changes in the integrity and percentage distribution of the active constituents. This finding was in agreement with the findings of earlier researchers, who showed that enzyme assisted extraction can lead to an increase in oil yield as well as slight modification in the biochemical properties of the extracted oil [36].

The biochemical composition of extracted oil also differed from the previous studies. Ali et al. extracted seed oil with the compositions of palmatic acid $(4.84 \pm 0.13 \%)$, stearic acid $(20.21 \pm 0.40 \%)$, linoleic acid $(6.37 \pm 0.46 \%)$, and eleostearic acid $(53.22 \pm 0.36 \%)$ [37]. Meanwhile, the seed oil being extracted using AEE had a higher amount of palmitic acid. In addition, the saturated fatty acid, stearic 
acid, was only detected in M2. Additionally, the omega-3 fatty acid detected by Ali et al. was eleostearic acid, whilst in the oil extracted using AEE, the highly unsaturated stearidonic acid was detected.

The lignin, soluble sugar, and uronic acid contents of the EFM were determined. Lignin consists of a very complex structure which is difficult to cleave [38]. The lignin content of the EFM; M0, M1 (15.91 $\%)>$ M2 $(15.06 \%)>$ M4 $(14.71 \%)>$ M3 (14.54\%) did not show any significant changes with the presence of enzymes in AEE. Different types of soluble sugars and uronic acid were released and further analyzed with HPAEC-PAD. The results are presented in Table 5. The main soluble sugar composition of EFM was glucose (rt. $15.90 \mathrm{~min}$ ) and rhamnose (rt. $10.42 \mathrm{~min}$ ), respectively. No definite trend was shown between the percentage of enzyme ratios used with the percentage distribution of soluble sugars and uronic acid obtained. M0L showed the lowest amount of acid galacturonic (rt. $31.87 \mathrm{~min}, 8.42 \%$ ). The percentage of acid galacturonic increased with the presence of enzyme cocktails in $\mathrm{M} 3_{\mathrm{L}}(16.12 \%)<\mathrm{M} 4_{\mathrm{L}}$ $(16.37 \%)<\mathrm{M}_{\mathrm{L}}(22.00 \%)<\mathrm{M} 2_{\mathrm{L}}(22.25 \%)$. These results suggested that the presence of pectinase in the enzyme cocktail X7 facilitated the breakdown of cell wall pectic polysaccharides into simpler molecules like acid galacturonic [39-41]. The concentration of glucose in M0 was only $57 \%$. The percentage of glucose increased with the introduction of enzyme cocktails; M3 $(65.42 \%)<$ M4 $(66.77 \%)$ $<$ M1 $(71.34 \%)<$ M2 $(76.20 \%)$. These results indicated that more cellulose from the cell wall was cleaved into different types of sugars (glucose, xylose, galactose, arabinose, rhamnose, mannose, and fucose) with the help of the enzyme cocktails [42-44].

Table 5 Sugar analysis of EFM by HPAEC-PAD.

\begin{tabular}{|c|c|c|c|c|c|c|c|c|c|c|c|}
\hline \multirow{2}{*}{ Sam } & \multirow{2}{*}{ HEL1 } & \multirow{2}{*}{$\mathbf{X} 7$} & \multicolumn{9}{|c|}{ Percentage of yield (\%) } \\
\hline & & & Glu & Xyl & Galac & Ara & Rham & Man & Fuc & Ac. Galac & Ac. Gluc \\
\hline M0 & & & 57.00 & 19.02 & 4.21 & 3.95 & 1.70 & 1.09 & 0.42 & 11.77 & 0.83 \\
\hline $\mathrm{M}_{\mathrm{L}}$ & & & 0.61 & 1.84 & 7.60 & 6.98 & 62.98 & 6.41 & 2.40 & 8.42 & 2.77 \\
\hline M1 & \multirow[b]{2}{*}{5} & \multirow[b]{2}{*}{-} & 71.34 & 13.85 & 2.57 & 2.28 & 1.07 & 0.91 & 0.25 & 7.31 & 0.42 \\
\hline $\mathrm{M} 1_{\mathrm{L}}$ & & & 1.29 & 2.67 & 9.17 & 10.37 & 35.36 & 12.64 & 5.24 & 22.00 & 1.26 \\
\hline M2 & \multirow{2}{*}{5} & \multirow{2}{*}{1.25} & 76.20 & 10.36 & 2.60 & 1.98 & 1.06 & 0.79 & 0.17 & 6.54 & 0.30 \\
\hline $\mathrm{M} 2_{\mathrm{L}}$ & & & 1.10 & 2.32 & 9.16 & 9.40 & 37.26 & 12.62 & 4.54 & 22.25 & 1.34 \\
\hline M3 & \multirow[b]{2}{*}{5} & \multirow{2}{*}{2.5} & 65.42 & 22.34 & 2.72 & 3.37 & 1.41 & 0.78 & 0.18 & 2.94 & 0.83 \\
\hline $\mathrm{M} 3_{\mathrm{L}}$ & & & 0.57 & 1.19 & 8.92 & 7.13 & 48.00 & 13.16 & 3.94 & 16.12 & 0.96 \\
\hline M4 & \multirow{2}{*}{5} & \multirow{2}{*}{5} & 66.77 & 22.06 & 2.48 & 2.77 & 1.21 & 1.00 & 0.17 & 2.69 & 0.85 \\
\hline $\mathrm{M}_{\mathrm{L}}$ & & & 0.61 & 1.66 & 7.96 & 5.95 & 48.34 & 14.40 & 2.93 & 16.37 & 1.79 \\
\hline
\end{tabular}

Note: $\mathrm{M}$ refers to the EFM, which had undergone AEE. ${ }_{\mathrm{L}}$ refers to the soluble sugar and uronic acid sample of the EFM.

The hemicellulose content of the seed biomass was determined. M0 produced the highest percentage of hemicellulose $(16.98 \%)$. The percentage of hemicellulose decreased slightly with the presence of enzyme cocktails; M1 (14.23\%), M2 (13.44\%), M3 (13.41\%), and M4 (12.98\%). Despite significant knowledge in the synergism among cellulase and enzyme cocktail components, a full mechanistic understanding of lignocellulose hydrolysis by cellulolytic enzymes is still limited and needs further refinement $[45,46]$. The variation in the hemicellulose composition showed that, as a 
polysaccharide of simpler structure than cellulose, hemicellulose was also prone to breakdown with the presence of hemicellulase [47].

The results of further analysis of hemicellulase obtained using FTIR spectroscopy are shown in Figure 2. The FTIR spectrum showed that there were differences in the peak intensity and between the absorption bands obtained. According to the Beer-Lambert law, the higher is the concentration; the stronger is the peak intensity [48]. The absorption of 3272, 2927, 1628, 1416, 1239, and $1038 \mathrm{~cm}^{-1}$ peaks represented the characteristic absorption of hemicellulose [49]. The broad absorption band at $\sim 3272 \mathrm{~cm}^{-1}$ usually represents the $\mathrm{O}-\mathrm{H}$ or the absorption of a large number of individual molecules, such that hydrogen is bonded to a slightly different compound.

Meanwhile, the absorption band $\sim 2927 \mathrm{~cm}^{-1}$ indicated the presence of saturated carbon band, C-H. The band $\sim 1737 \mathrm{~cm}^{-1}$ referred to the stretching band of a carbonyl group. The absorption that appeared in $\sim 1628 \mathrm{~cm}^{-1}$ is usually associated with the absorbed water [50]. A small peak at $\sim 1737 \mathrm{~cm}^{-1}$ could be attributed to the acetyl groups of the hemicellulose. A strong band that appeared at $\sim 1038 \mathrm{~cm}^{-1}$ could be assigned to $\mathrm{C}-\mathrm{OH}$ bending in xylan, attributed to the dominant presence of xylan, one of the 3 main subgroups of hemicellulose with the backbone of $1-4$ linked $\beta$-D-pyranose attributed to the presence of xylan-type hemicellulose in $M$. charantia seed [51].

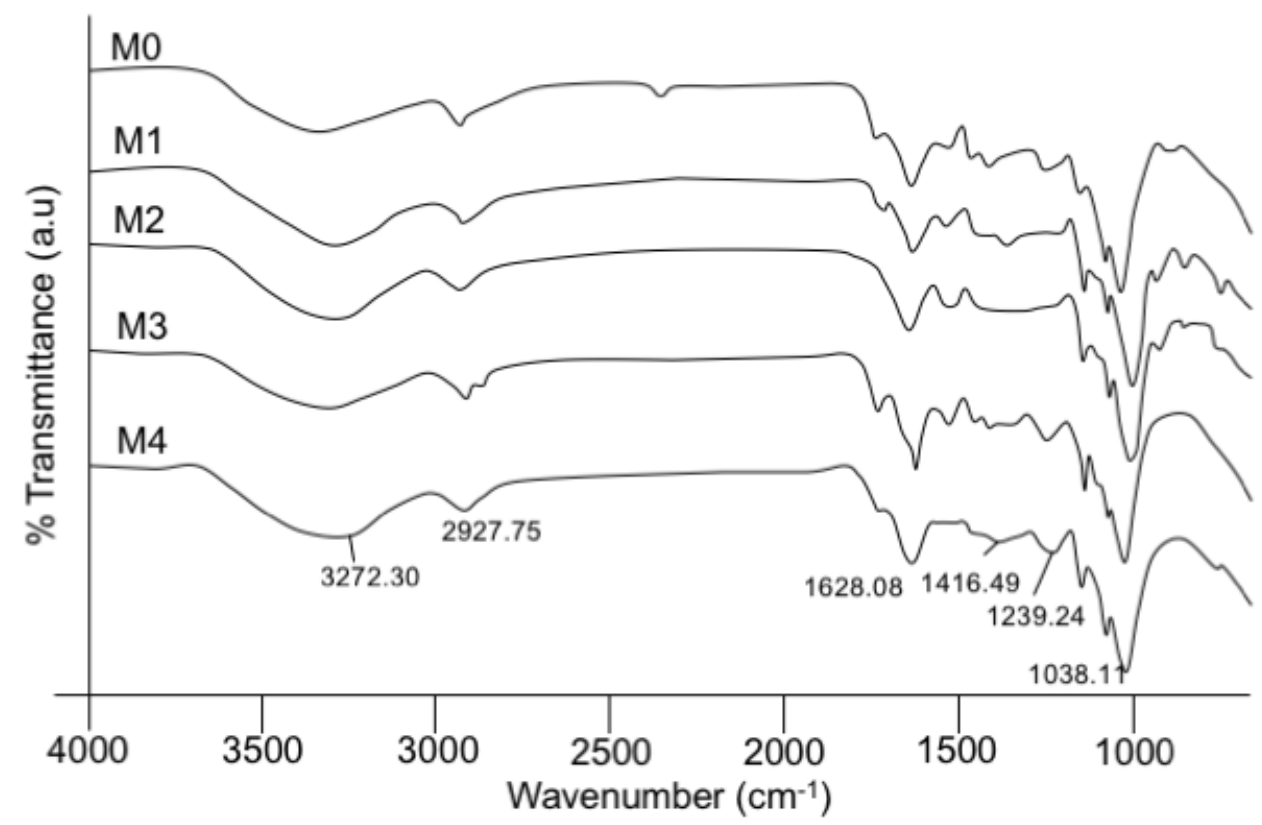

Figure 2 FTIR spectra of hemicellulose.

The extracted hemicellulose was then subjected to SEC analysis to evaluate the effects of the enzymes on their molecular mass distribution. Figure 3 shows the size exclusion chromatogram of the extracted samples. 


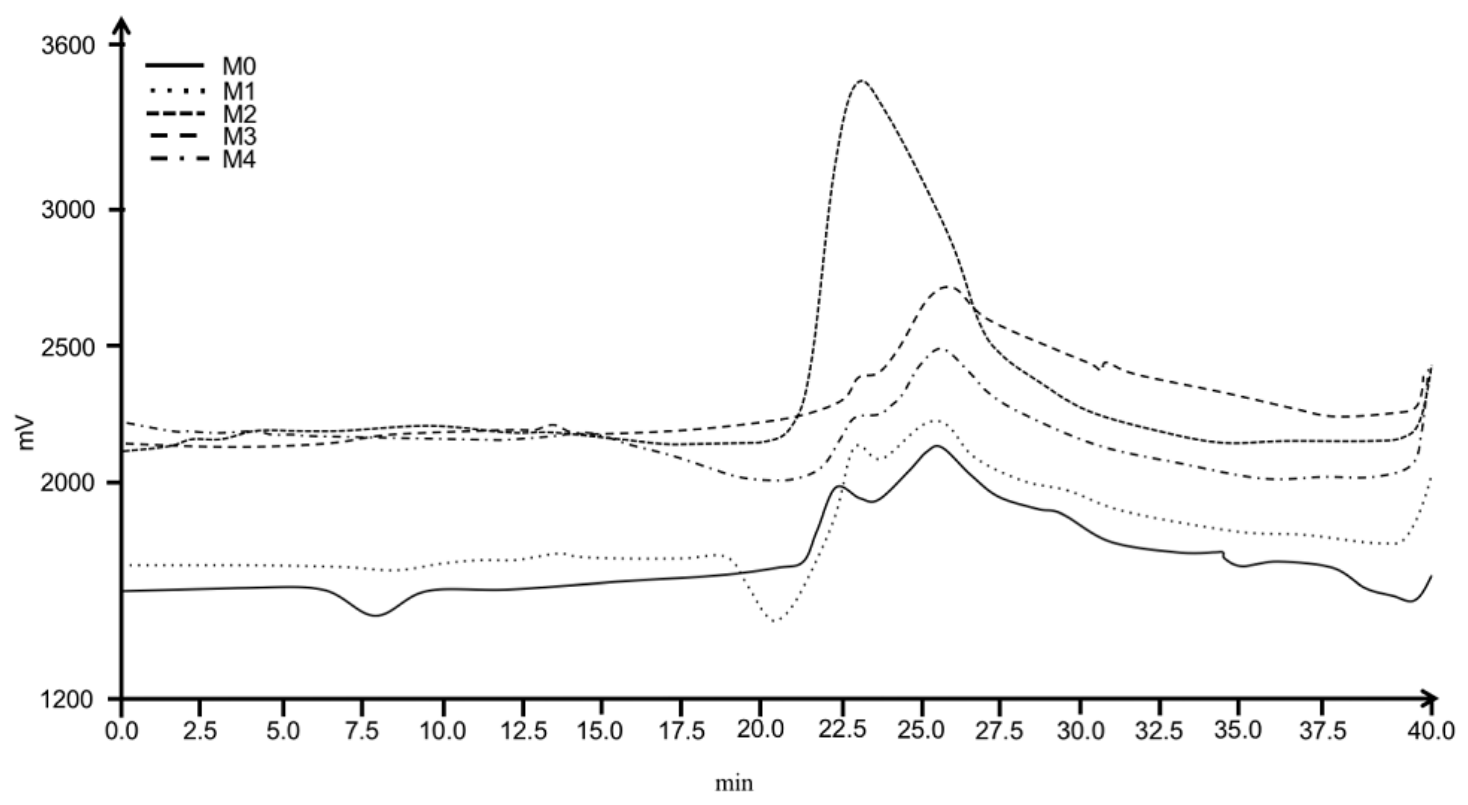

Figure 3 Size exclusion chromatogram of hemicellulose from different Momordica charantia seed extracted free materials.

Each extracted sample was observed to have a slightly different molecular mass distribution trend. The difference in the molecular mass distribution trend could be due to the effects of different enzymes towards the induction of different transformations in cellulose size. M0 had the highest weight average $\left(\mathrm{M}_{\mathrm{w}}\right)$ of 447,148 - 457,148 $\mathrm{gmol}^{-1}$, followed by M4 $\left(\mathrm{M}_{\mathrm{w}}: 36,186-378,116 \mathrm{gmol}^{-1}\right), \mathrm{M} 3\left(\mathrm{M}_{\mathrm{w}}: 120,339\right.$ $\left.\mathrm{gmol}^{-1}\right)$, M1 $\left(\mathrm{M}_{\mathrm{w}}: 87,865 \mathrm{gmol}^{-1}\right)$, and lastly $\mathrm{M} 2\left(\mathrm{M}_{\mathrm{w}}: 55,915 \mathrm{gmol}^{-1}\right)$. These results indicated that the treatment degraded the macromolecular structure of hemicellulose to a noticeable extent with the incorporation of enzyme [47] as the hemicellulose obtained displayed higher molecular mass than that conventionally extracted, of $\sim 38,000$ and 56,000 $\mathrm{gmol}^{-1}$ in neutral and basic medium, respectively [52]. Sun et al. suggested that the extraction of high $\mathrm{M}_{\mathrm{w}}$ hemicelluloses was obtained with the coextraction of lignin-carbohydrates complexes [53]. In addition, the high hemicellulose polydispersity $\left(\mathrm{M}_{\mathrm{w}} / \mathrm{M}_{\mathrm{n}}\right)$ from M0 $\mathrm{M}_{\mathrm{w}} / \mathrm{M}_{\mathrm{n}}$ of $1.15-7.17$, to M2 $\mathrm{M}_{\mathrm{w}} / \mathrm{M}_{\mathrm{n}}$ of 6.06 , to $\mathrm{M} 4 \mathrm{M}_{\mathrm{w}} / \mathrm{M}_{\mathrm{n}}$ of $1.9-21.72$, to $\mathrm{M} 1 \mathrm{M}_{\mathrm{w}} / \mathrm{M}_{\mathrm{n}}$ of 107.71, and lastly to $M 3 \mathrm{M}_{\mathrm{w}} / \mathrm{M}_{\mathrm{n}}$ of 284.30 indicated a wide molecular weight distribution, which might be caused by hemicellulose chain aggregation $[54,55]$.

\section{Conclusions}

The adaptation of the AEE method successfully aided the extraction of $M$. charantia seed oil utilizing the combination of HEL1 and X7 enzyme cocktails. The presence of enzymes disrupted the cell wall into simpler molecules (i.e., glucose, xylose, etc.) and facilitated the oil released. The introduction of the enzyme in the extraction process slightly changed the molecular mass distribution of the lignocellulosic biomass. Improved analytical methods are needed to characterize further, analyze, and study the biomass composition and enzyme mechanisms. This study proved that $M$. charantia seed contain significant contents of fatty acids, sugars, and hemicellulose, which can be further utilized to develop sustainable products such as biofuel, membrane, and biodegrade plastic. 


\section{Acknowledgements}

The authors thank Dr. Isabelle Ziegler-Devin from LERMAB, University of Lorraine, France, in aiding with the HPAEC-PAD and SEC analysis. as well as Biolie, France, in assisting with the AEE and GC-MS analysis. The authors also thank the Malaysian Government, French Embassy Malaysia, Université de Lorraine, and Universiti Sains Malaysia for the financial support of this study through the Research University Grant RUI: 1001/PKIMIA/8011072.

\section{References}

[1] TK Behera, S Behera, LK Bharathi, KJ John, PW Simon and JE Staub. Horticulture reviews. In: J Janick (Ed.). Bitter Gourd: Botany, Horticulture, Breeding. Wiley Blackwell, 2010, p. 101-41.

[2] A Donya, N Hettiarachchy, R Liyanage, JJ Lay, P Chen and M Jalaluddin. Effects of processing methods on the proximate composition and momordicosides $\mathrm{K}$ and $\mathrm{L}$ content of bitter melon vegetable. J. Agric. Food Chem. 2007; 55, 5827-33.

[3] PR Dandawate, D Subramaniam, SB Padhye and S Anant. Bitter melon: A panacea for inflammation and cancer. Chin. J. Nat. Med. 2016; 14, 81-100.

[4] K Abascal and E Yarnell. Using bitter melon to treat diabetes. J. Altern. Compl. Ther. 2005; 11, 179-84.

[5] TE Shain, A Abdullah and K Kassim. Extraction of steroidal glycoside from small-typed bitter gourd (Momordica charantia L.). J. Chem. Pharm. Res. 2015; 7, 870-8.

[6] B Joseph and D Jini. Antidiabetic effects of Momordica charantia (bitter melon) and its medicinal potency. Asian Pac. J. Trop. Dis. 2013; 3, 93-102.

[7] S Desai and P Tatke. Charantin: An important lead compound from Momordica charantia for the treatment of diabetes. J. Pharmacogn. Phytochem. 2015; 3, 163-6.

[8] TB Ng, WW Li and HW Yeung. Effects of ginsenosides, lectins and Momordica charantia insulinlike peptide on corticosterone production by isolated rate adrenal cells. J. Ethnopharmacol. 1987; 21, 21-9.

[9] GT Zhao, JQ Liu, YY Deng, HZ Li, JC Chen, ZR Zhang, L Zhou and MH Qiu. Cucurbitane-type triterpenoids from the stems and leaves of Momordica charantia. Fitoterapia 2014; 95, 75-82.

[10] JQ Cao, Y Zhang, JM Cui and YQ Zhao. Two new cucurbitane triterpenods from Momordica charantia L. Chin. Chem. Lett. 2011; 22, 583-6.

[11] Y Tasui, M Hosokawa, T Sahara, R Suzuki, S Ohgiya, H Kohno, T Tanaka and K Miyashita. Bitter gourd seeds fatty acid rich in $9 c, 11 t, 13 t$-conjugated linolenic acid induces apoptosis and upregulates the GADD45, p53 and PPAR $\gamma$ in human colon cancer Caco-2 cells. Prostaglandins Leukot. Essent. Fatty Acids 2005; 73, 113-9.

[12] L Liu, EG Hammond and BJ Nikolau. In Vivo studies of the biosynthesis of a-eleostearic acid in the seed of Momordica charantia L. Plant Physiol. 1997; 113, 1343-9.

[13] A Elagizi, CJ Lavie, K Marshall, JJ DiNicolantonio, JH O'Keefe and RV Milani. Omega-3polyunsaturated fatty acids and cardiovascular health: A comprehensive review. Prog. Cardiovasc. Dis. 2018; 61, 76-85.

[14] E Balk, M Chung, A Lichtenstein, P Chew, B Kupelnick, A Lawrence, DD Vine and J Lau. Effects of omega-3 fatty acids on cardiovascular risk factors and intermediate markers of cardiovascular disease. Evid. Rep. Technol. Assess. 2004; 93, 1-6.

[15] GC Chen, HM Su, YS Lin, PY Tsou, JH Chyuan and PM Chao. A conjugated fatty acid present at high levels in bitter melon seed favorably affects lipid metabolism in hepatocytes by increasing $\mathrm{NAD}^{+} / \mathrm{NADH}$ ratio and activating PPAR $\alpha$, AMPK and SIRT1 signalling pathway. J. Nutr. Biochem. 2016; 33, 28-35.

[16] Department of Agriculture, Putrajaya, Malaysia. Vegetables and cash crops statistic. Department of Agriculture, Putrajaya, Malaysia, 2014. 
[17] G Sodeifian, NS Ardestani, SA Sajadian and K Moghadamian. Properties of Portulaca oleracea seed oil via supercritical fluid extraction: Experimental and optimization. J. Supercrit. Fluids 2018; 135, 34-44.

[18] MM Yusoff, MH Gordon, O Ezeh and K Niranjan. Aqueous enzymatic extraction of Moringa oleifera oil. Food Chem. 2016; 211, 400-8.

[19] RC Kumar, MM Benal, BD Prasad, MS Krupashankara, RS Kulkarni and NH Siddaligaswamy, Microwave assisted extraction of oil from Pongamia pinnata seeds. Mater. Today Proc. 2018; 5, 2960-4.

[20] RA Sheldon and SV Pelt. Enzyme immobilisation in biocatalysis: Why, what and how. Chem. Soc. Rev. 2013; 42, 6223-35.

[21] KW Waldron, ML Parker and AC Smith. Plant cell walls and food quality. Compr. Rev. Food Sci. Food Saf. 2003; 2, 101-19.

[22] NC Carpita and DM Gibeaut. Structural models of primary cell walls in flowering plants: Consistency of molecular structure with the physical properties of the walls during growth. Plant $J$. 1993; 3, 1-30.

[23] A Rosenthal, DL Pyle and K Niranjan. Aqueous and enzymatic processes for edible oil extraction. Enzyme Microb. Technol. 1996; 19, 402-20.

[24] S Latif and F Anwar. Aqueous enzymatic sesame oil and protein extraction. Food Chem. 2011; 125, 679-84.

[25] L Muniglia, M Girardin, B Piffaut and G Ricochon. WO2011/045387 A1. Institut National De La Propriété Industrielle. 2011, Available at http://patentscope.wipo.int/search/en/WO2011045387, accessed March 2020.

[26] LD Metcalfe and AA Schmitz. The rapid preparation of fatty acid esters for gas chromatographic analysis. Anal. Chem. 1961; 33, 363-4.

[27] M Chadni, N Grimi, O Bals, I Ziegler-Devin and N Brosse. Steam explosion process for the selective extraction of hemicelluloses polymers from spruce sawdust. Ind. Crop. Prod. 2019; 141, 111757.

[28] KC Baby and TV Ranganathan. Effect of enzyme pre-treatment on extraction yield and quality of cardamom (Elettaria cardamomum maton) volatile oil. Ind. Crop. Prod. 2016; 89, 200-6.

[29] QY Gai, J Jiao, PS Mu, W Wang, M Luo, CY Li, YG Zu, FY Wei and YJ Fu. Microwave-assisted aqueous enzymatic extraction of oil from Isatis indigotica seeds and its evaluation of physicochemical properties, fatty acid compositions and antioxidant activities. Ind. Crop. Prod. 2013; 45, 303-11.

[30] GPP Kamatou and AM Viljoen. Comparison of fatty acid methyl esters of palm and palmist oils determined by GCxGC-ToF-MS and GC-MS/FID. S. Afr. J. Bot. 2017; 112, 483-8.

[31] SN Baharum, H Bunawan, MA Ghani, WAW Mustapha and NM Noor. Analysis of the chemical composition of the essential oil of Polygonum minus Huds. Using two-dimensional gas chromatography-time-of-flight mass spectrometry (GC-TOF MS). Molecules 2010; 15, 7006-15.

[32] AR White and RM Brown. Enzymatic hydrolysis of cellulose: Visual characterization of the process. Proc. Natl. Acad. Sci. USA 1981; 78, 1047-51.

[33] C Wu, Y Xiao, W Lin, J Li, S Zhang, J Zhu and J Rong. Aqueous enzymatic process for cell wall degradation and lipid extraction from Nannochloropsis sp. Bioresour. Technol. 2017; 223, 312-6.

[34] A Zuorro, V Malavasi, G Cao and R Lavecchia. Use of cell wall degrading enzymes to improve the recovery of lipids from Chlorella sorokiniana. Chem. Eng. J. 2019; 377, 120325.

[35] JJ Liu, MAA Gasmalla, P Li and R Yang. Enzyme-assisted extraction processing from oilseeds: Principle, processing and application. Innov. Food Sci. Emerg. Technol. 2016; 35, 84-193.

[36] SM Abdulkarim, K Long, OM Lai, SKS Muhammad and HM Ghazali. Some physico-chemical properties of Moringa oleifera seed oil extracted using solvent and aqueous enzymatic methods. Food Chem. 2005; 93, 253-63.

[37] MA Ali, MA Sayeed, MS Reza, MS Yeasmin and AM Khan. Characteristics of seed oils and nutritional compositions of seeds from different varieties of Momordica charantia Linn. cultivated in Bangladesh. Czech J. Food Sci. 2008; 26, 275-83. 
[38] CM Welker, VK Balasubramanian, C Petti, KM Rai, S DeBolt and V Mendu. Review: Engineering plant biomass lignin content and composition for biofuels and bioproducts. Energies 2015; 8, 765476.

[39] A Biz, FC Farias, FA Motter, DH de Paula, P Richard, N Krieger and DA Mitchell. Pectinase activity determination: An early deceleration in the release of reducing sugars throws a spanner in the works. PLoS One 2014; 9, 1-8.

[40] DB Pedrolli, AC Monteiro, E Gomes and EC Carmona. Pectin and Pectinases: Production, characterization and industrial application of microbial pectinolytic enzymes. Open Biotechnol. J. 2009; 3, 9-18.

[41] L Liu, Y You, H Deng, Y Guo and Y Meng. Promoting hydrolysis of apple pomace by pectinase and cellulase to produce microbial oils using engineered Yarrowia lipolytica. Biomass Bioenerg. 2019; 126, 62-9.

[42] F Segato, ARL Damásio, RC de Lucas, FM Squina and RA Prade. Genomics review of holocellulose deconstruction by aspergilli. Microbiol. Mol. Biol. Rev. 2014; 78, 588-613.

[43] L Zhong, JF Matthews, MF Crowley, T Rignall, C Talón, JM Cleary, RC Walker, G Chukkapalli, CM Cabe, MR Nimlos, CL Brooks, ME Himmel and JW Brady. Interactions of the complete cellobiohydrolase I from Trichoderma reesei with microcrystalline cellulose I $\beta$, Cellulose 2008; 15, 261-73.

[44] Y Wei, D Wu, D Wei, Y Zhao, J Wu, X Xie, R Zhang and Z Wei. Improved lignocellulosedegrading performance during straw composting from diverse sources with actinomycetes inoculation by regulating the key enzyme activities. Bioresour. Technol. 2019; 271, 66-74.

[45] J Nill, N Karuna and T Jeoh. The impact of kinetic parameters on cellulose hydrolysis rates. Process Biochem. 2018; 74, 108-17.

[46] B Yang, Z Dai, SY Ding and CE Wyman. Enzymatic hydrolysis of cellulosic biomass. Biofuels $2011 ; 2,421-50$.

[47] J Zhao, Z Dong, J Li, L Chen, Y Bai, Y Jia and T Shao. Ensiling as pretreatment of rice straw: The effect of hemicellulase and Lactobacillus plantarum on hemicellulose degradation and cellulose conversion. Bioresour. Technol. 2018; 266, 158-65.

[48] PF Ávila, MBS Forte and R Goldbeck. Evaluation of the chemical composition of a mixture of sugarcane bagasse and straw after different pre-treatments and their effects on commercial enzyme combinations for the production of fermentable sugars. Biomass. Bioenerg. 2018; 116, 180-8.

[49] CM Popescu, MC Popescu and C Vasile. Characterization of fungal degraded lime wood by FT-IR and 2D IR correlation spectroscopy. Microchem. J. 2010; 95, 377-87.

[50] X Peng, J Bian, M Li, X Xiao, X Xia, W Yin and R Sun. Graded ethanol fractionation and structural characterization of alkali-extractable hemicelluloses from Olea europaea L. Bioresources 2013; 8, 1110-23.

[51] DS Naidu, SP Hlangothi and MJ John. Bio-based products from xylan: A review. Carbohydr. Polym. 2018; 179, 28-41.

[52] M Chadni, O Bals, I Ziegler-Devin, N Brosse and N Grimi. Microwave-assisted extraction of highmolecular-weight hemicelluloses from spruce wood. Comptes Rendus Chimie 2019; 22, 574-84.

[53] R Sun, JM Lawther and WB Banks. Fractional and structural characterization of wheat straw hemicelluloses. Carbohydr. Polym. 1996; 29, 325-31.

[54] T Eremeeva. Size-exclusion chromatography of enzymatically treated cellulose and related polysaccharides: A review. J. Biochem. Bioph. Meth. 2003; 56, 253-64.

[55] MS Izydorczyk and CG Biliaderis. Cereal arabinoxylans: Advances in structure and physicochemical properties. Carbohydr. Polym. 1995; 28, 33-48. 